\title{
Assessment of the effects of dysphagia therapy in patients in the early post-stroke period: a randomised controlled trial
}

\author{
Edyta Krajczy ${ }^{1}$, Marcin Krajczy ${ }^{1,2}$, Jacek Luniewski ${ }^{2}$, Katarzyna Bogacz ${ }^{2}$, Jan Szczegielniak ${ }^{2}$ \\ ${ }^{1}$ General Surgery Department, Municipal Hospital in Nysa, Poland \\ ${ }^{2}$ Physiotherapy Department, Opole University of Technology, Opole, Poland
}

\begin{abstract}
Aim: This study aimed to evaluate the effects of dysphagia therapy in patients in the early post-stroke period.

Clinical rationale: Dysphagia can be one of the consequences of stroke. This problem often leads to complications in the early stages of stroke, including aspiration pneumonia. Although individual reports on dysphagia exist in the literature, no comprehensive guidelines for dysphagia therapy are available.

Material and methods: This randomised controlled trial included 60 patients with swallowing difficulties after ischaemic stroke (30 each in the study and control groups; age range: 55-65 years) who were admitted to a hospital stroke subunit. Patient rehabilitation period covered 15 days (seven days a week), with therapy for the first 10 days provided during patient hospitalisation and then outpatient physiotherapy during the subsequent five days. The procedure, including providing education about safe food and liquid consumption to patients and their caregivers, was performed in both patient groups. An original dysphagia treatment method was employed in the study group. Statistical average, standard deviation, and statistical error before and after therapy were determined in the study and control groups. The significance of differences in results between the study and control groups was assessed using the Mann-Whitney $U$ test.

Results: The applied therapy for dysphagia improved the swallowing function and selected motor functions of patients after stroke. In the study group, ineffective (delayed) and absent swallowing reflex was observed in 13 patients (44\%) before therapy and in one patient (3\%) after therapy. The rate of effective swallowing reflex increased from $57 \%$ to $97 \%$. Statistically significant differences in swallowing reflex were observed between the study and control groups after therapy $(p=0.00001)$.
\end{abstract}

Conclusions: A comprehensive therapy for dysphagia is effective and can reduce serious complications of swallowing disorders in clinical practice.

Clinical implications: The results of this study could improve the clinical treatment of dysphagia.

Key words: dysphagia; swallowing; stroke; physiotherapy; neurology

(Neurol Neurochir Pol 2019; 53 (6): 428-434)

\section{Introduction}

Brain stroke poses serious medical and social problems, and is one of the most frequent causes of disability and mortality in adults. The incidence of brain stroke is growing, and the mortality rate during the first weeks after stroke is high. The most frequent complications of brain stroke include hemiparesis, aphasia, behavioural disorders, and dysphagia [1-3]. In post-stroke patients, the presence of clinically manifested dysphagia is, to a high degree, decisive in terms of their survival [4-7].
Early diagnosis and application of suitable therapeutic procedures reduce the effects of swallowing disorders and limit mortality due to post-stroke dysphagia. The objective of physical therapy for dysphagia is to prevent aspiration, dehydration, and malnutrition via the restoration of functional and physiological swallowing [8-10].

\section{Clinical rationale for the study}

Aspiration pneumonia is the most frequent cause of death in patients with neurogenic dysphagia [11]. We believe, based 
on available studies in the literature, that no comprehensive study to date has investigated the effects of swallowing and feeding therapy and of food and liquid supplementation on the recovery of patients with dysphagia [12]. Hence, we decided to evaluate the effects of dysphagia therapy in post-stroke patients during the rehabilitation process. Owing to the lack of a standardised method for patients with dysphagia, an original treatment method based on the available literature, and on our own practical experience, was developed. We believe that the method, including compensation positions, swallowing reflex stimulation, exercises that improve facial muscles, breathing exercises, and patient education concerning safe swallowing and selection of appropriate food consistency, might improve the respective phases of swallowing and increase patient awareness and involvement in the rehabilitation process.

This study aimed to evaluate the effects of dysphagia therapy in patients in the early post-stroke period. Furthermore, it was intended to answer the following research questions: (1) Does the swallowing reflex improve after dysphagia therapy?; and (2) Does dysphagia therapy in patients after brain stroke improve the swallowing function?

\section{Study material and methods}

\section{Research material}

This study enrolled patients aged 55 to 65 with swallowing disorders after ischaemic brain stroke who were admitted to the Department of Neurology's Stroke Subunit of the Municipal Hospital in Nysa from April 2015 to March 2018. The study included patients who (1) were in the early post-stroke (first stroke) period (i.e. up to 30 days after falling ill); (2) had swallowing disorders and were able to cooperate; (3) were assessed using the National Institutes of Health Stroke Scale (conscious or napping but waking upon minor stimulation, aware of month and age, able to follow orders, with small or partial paralysis of the facial nerve, without aphasia or with mild or moderate aphasia, without dysarthria or with mild or moderate dysarthria); (4) had level 4 dysphagia according to the Swallowing Rating Scale (SRS); and (5) had no dementia based on the Mini-Mental State Examination (MMSE) scale. All patients underwent a psychological consultation to assess their degree of dementia using the MMSE scale. Conversely, patients with a second or third brain stroke (more than 30 days after falling ill), level 1-3 dysphagia or level 5-7 dysphagia according to the SRS, cognitive function disorders that make cooperation impossible (MMSE < 25), total aphasia, anarthria, and bilateral facial nerve paralysis, and those in whom a tracheostomy tube was inserted, were excluded from the study.

All patients were given CT neuroimaging tests which showed similar symptoms in terms of the affected structures, location and extent of the stroke. Patients with extensive ischaemia lesions were excluded from the study (TACI - total anterior circulation infarct; based on the ischaemia lesion classification). The study included patients with acute stage of ischaemic stroke diagnosed in CT imaging. Patients diagnosed with hyperacute, subacute and chronic stage of stroke were excluded from the research. None of the patients, resulting from contraindications, was administered alteplase. The patients did not manifest secondary haemorrhage.

\section{Methods}

A total of 60 patients consented to participate in the study, and were equally assigned to study and control groups (30 patients each) (Tab. 1). Patients were randomly assigned using a computer randomisation program (ALEA).

The project was positively assessed by the Bioethics Committee of Opole Medical Chamber (resolution no. 213, dated March 25, 2015) and all study participants provided informed consent.

The patient rehabilitation period covered 15 days (seven days a week); therapy for the first 10 days was provided at the Department of Neurology's Stroke Subunit during patient hospitalisation, and patients received outpatient physiotherapy during the subsequent five days.

Education about safe food and liquid intake was provided to patients from both groups and their caregivers. Both groups received neurological physiotherapy depending on patient dysfunction. The therapy included passive, assisted, and supported exercises, respiration exercises, assumption of erect posture, walking re-education, and training based on the NDT Bobath and PNF methods. Furthermore, patients in the study group were subjected to an original dysphagia treatment method.

Examinations including assessment of dysphagia and motor function were performed on the first day of hospitalisation and again after physiotherapy.

\section{Assessment of the swallowing function}

Timed test of swallowing was used to assess the swallowing function and was performed on the first and last days of therapy. The following parameters were evaluated: (1) voice quality before the test and after the patient had drunk $50 \mathrm{~mL}$ of water without taking their lips away from the cup; (2)

Table 1. Examined patients after ischaemic brain stroke in study and control groups (study material)

\begin{tabular}{|c|c|c|c|c|c|c|c|c|c|}
\hline \multirow[b]{2}{*}{ Group } & \multirow[b]{2}{*}{$\begin{array}{c}\text { Number of } \\
\text { patients }\end{array}$} & \multirow[b]{2}{*}{ Women } & \multirow[b]{2}{*}{ Men } & \multicolumn{2}{|c|}{ Type of paresis } & \multicolumn{4}{|c|}{ Patient age } \\
\hline & & & & Right-sided & Left-sided & $\bar{\chi}$ & $\begin{array}{c}\text { Minimum age in } \\
\text { years }\end{array}$ & $\begin{array}{c}\text { Maximum age } \\
\text { in years }\end{array}$ & SD \\
\hline Study & 30 & 18 & 12 & 15 & 15 & 62.1 & 55 & 65 & 3.3 \\
\hline Control & 30 & 16 & 14 & 12 & 18 & 64.1 & 55 & 65 & 1.5 \\
\hline
\end{tabular}




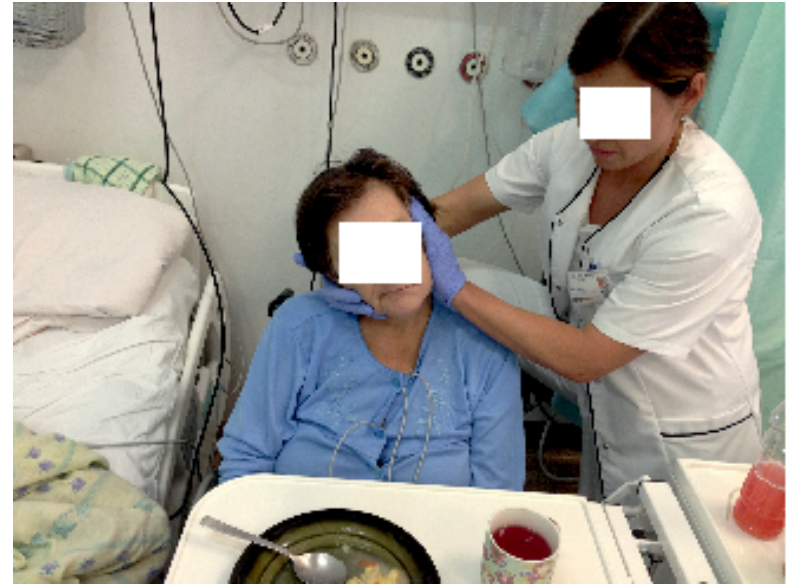

Figure 1. Compensation position to facilitate swallowing

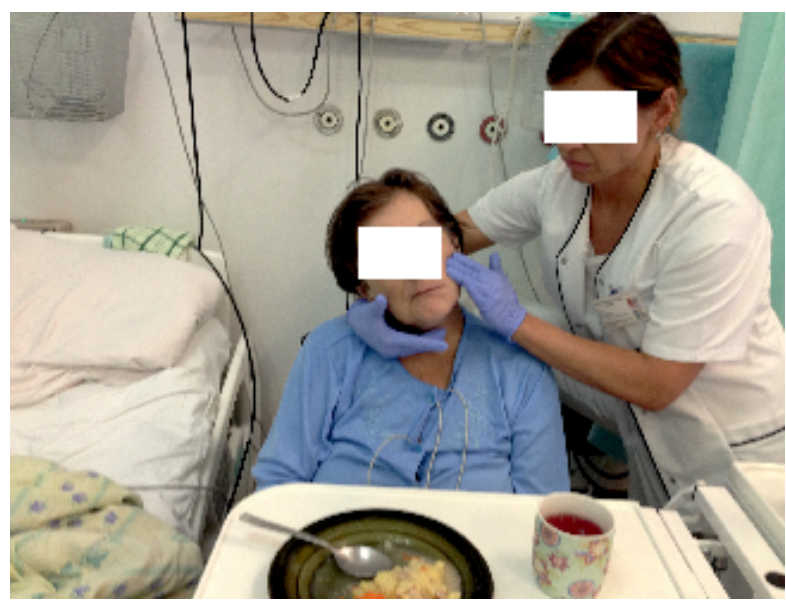

Figure 2. Cheek stimulation on the paretic side

swallowing time (in seconds); (3) number of swallows; and (4) saturation (to control liquid aspiration), which was measured using a device for gasometric studies (Beurer $\mathrm{GmbH}$, Ulm, Germany). $\mathrm{SpO}_{2}$ was measured for 5 min before drinking the liquid, and measurement was terminated at $5 \mathrm{~min}$ after drinking the tested substance.

\section{Assessment of the swallowing reflex}

Controlled swallowing was assessed after the patient swallowed blended food of uniform consistency. The swallowing reflex was categorised as either good, or delayed if the food was kept inside the mouth for a long period.

\section{Physiotherapy programme for patients with dysphagia}

Prior to the start of dysphagia physiotherapy, patients were observed while consuming their meals. The observation was followed by a palpatory examination. With an average duration of 60 min per day, therapy was provided daily for 15 days inclusive of holidays and included additional work with patients during every meal. The therapy was conducted in semi-sitting and sitting positions (sitting position away from the patient's bed starting from the third day after stroke), which was beneficial for the improvement in motor functions (control of the thorax and head).

Initially, a proper compensation position was selected to facilitate swallowing (Fig. 1). While patients were eating their meal, stimulation to the cheek on the paretic side was applied to prevent food deposition in the area (Fig. 2).

Patients received therapy aimed at restoring the chewing and swallowing functionality, which included exercises that strengthened the orbicularis oris, risorius, levator labii superioris, depressor labii inferioris, genioglossus, hypoglossus, styloglossus, and buccinator, as well as breathing exercises and sensory stimulation. The exercises for the strengthening of the orbicularis oris, risorius, and levator labii superioris included alternate narrowing and extending of the lips (10 repetitions); sucking in of air using a straw (several repetitions); and resistance exercises which involved closure of lips so as to allow removal of a wooden spatula placed flat between the lips (10 repetitions), lifting of the closed upper lip on the paretic side and, as reference, on the healthy side (10 repetitions), and lifting of the lower lip similar to the previous exercise (10 repetitions).

The exercises for the strengthening of the genioglossus, hypoglossus, and styloglossus included alternate touching of the upper and lower teeth with the tongue (10 repetitions); alternate touching of the corners of the mouth using the tip of the tongue (10 repetitions); pushing the tongue against a resisting wooden spatula (10 repetitions); fast and precise touching of the right corner of the mouth, middle of the upper lip, left corner of the mouth, and middle of the lower lip (10 repetitions); pushing against the spatula placed parallel to the lateral edge of the tongue (10 repetitions); resistance exercises applied to the middle of the tongue using a spatula in which the patient was asked to attempt to lift the back of the tongue toward the palate (10 repetitions), which were exercises for improving the function of the tongue's vertical muscle (very important for transporting a bolus of food); pushing the tongue against the cheeks (10 repetitions); and gently biting the tip of the tongue with the teeth and attempting to swallow deeply while maintaining that position (10 repetitions), which served as exercises for the tongue base.

The exercises for the strengthening of the buccinator muscle included filling the cheeks with air and retracting them, transferring air from one cheek to the other, and exercises that improved the tension in the cheek muscles (resistance attempt against the expansion of the cheek with a spatula placed in the vestibule). All exercises were repeated 10 times.

Respiration exercises were performed to improve laryngeal closure during swallowing, and included exercises involving intentional deep inhaling and breath holding; exercises to enhance exhaling in which a long straw immersed in a bottle of water was used; exercises for correct respiration pathway 
Table 2. Number of patients with effective, ineffective, or absent swallowing reflex before and after therapy in study and control groups, and assessment of differences in occurrence

\begin{tabular}{|c|c|c|c|c|c|c|c|}
\hline \multicolumn{2}{|c|}{ Swallowing reflex } & \multicolumn{3}{|c|}{ Before therapy } & \multicolumn{3}{|c|}{ After therapy } \\
\hline & & $\begin{array}{l}\text { Study } \\
\text { group }\end{array}$ & $\begin{array}{l}\text { Control } \\
\text { group }\end{array}$ & Total & Study group & $\begin{array}{l}\text { Control } \\
\text { group }\end{array}$ & Total \\
\hline \multirow[t]{2}{*}{ Effective } & number & 17 & 15 & 32 & 29 & 15 & 44 \\
\hline & $\%$ & $56.67 \%$ & $50.00 \%$ & & $96.67 \%$ & $50.00 \%$ & \\
\hline \multirow[t]{2}{*}{ Ineffective (delayed) } & number & 11 & 15 & 26 & 1 & 15 & 16 \\
\hline & $\%$ & $36.67 \%$ & $50.00 \%$ & & $3.33 \%$ & $50.00 \%$ & \\
\hline \multirow[t]{2}{*}{ None } & number & 2 & 0 & 2 & 0 & 0 & 0 \\
\hline & $\%$ & $6.67 \%$ & $0.00 \%$ & & $0.00 \%$ & $0.00 \%$ & \\
\hline \multicolumn{2}{|l|}{ Chi-squared } & \multicolumn{3}{|c|}{$3.52 ; p=0.17$} & \multicolumn{3}{|c|}{$19.23 ; p=0.00001$} \\
\hline Total & & 30 & 30 & 60 & 30 & 30 & 60 \\
\hline
\end{tabular}

activating the diaphragm and intercostal muscles; exercises which involved deep and fast breathing in and slow breathing out; exercises which required holding in air and subsequently exhaling it rapidly; and exercises aimed to enable breathing in and holding air, swallowing, and strong breathing out with coughing. The duration of exercises was adjusted to patients' capabilities.

For patients with absent or delayed swallowing reflex, thermal stimulation to the palatine arches was applied using a laryngeal mirror previously cooled in ice (five stimulations, five swallows; similarly with the second palatine arch). To improve the sensation in the oral cavity, thermal stimulation using an ice cube was applied to areas of the cheeks and tongue and to the external side of the cheeks. Patients with delayed swallowing reflex and excessive tension in the hyoid bone area were subjected to mobilisation of the laryngohyoid complex.

\section{Statistical analysis}

Numerical characteristics and percentage rates were determined to evaluate the coughing reflex and voice quality based on the timed test of swallowing before and after therapy both in the study and control groups. Prior to the analysis, the Kolmogorov-Smirnov test was performed, which showed no distribution normality at a significance threshold of $\mathrm{p}<0.05$. This resulted in the selection of nonparametric statistical methods for statistical analysis.

Chi-squared test was used to assess whether coughing and voice quality based on the timed test of swallowing were significantly different between the research groups and whether their level in the study group was significantly different from that in the control group before and after therapy. The average, standard deviation, and standard error were determined to set the swallowing time, number of swallows, and blood oxygen saturation level $\left(\mathrm{SpO}_{2}\right)$ level before and after therapy.

The significance of differences between the results of the study and control groups was determined using the MannWhitney U test. Uniformity between both groups and distribution normality were evaluated using the Kolmogorov-Smirnov test, which were not confirmed at a significance threshold of $p<0.05$. The purpose of the test was to assess differences between the groups. The Mann-Whitney $U$ test was performed to capture the hidden multidimensional structure resulting from the dependent and independent variables. $Z$ statistics and significance threshold were presented.

\section{Results}

Assessment of the swallowing reflex

In the control group, the swallowing reflex was ineffective (delayed) and absent in 15 patients (50\%) at the initial assessment; this number of patients remained unchanged after 15 days. Conversely, effective swallowing reflex was observed in 15 patients $(50 \%)$ at the initial assessment, and no improvement in the swallowing reflex was noted after the observation.

In the study group, ineffective (delayed) and absent swallowing reflex was observed in 13 patients (44\%) before therapy and in one patient (3\%) after therapy (Tab. 2). The rate of effective swallowing reflex increased from $57 \%$ to $97 \%$.

No significant differences in swallowing reflex were observed between the study and control groups before therapy ( $p=0.17)$; however, statistically significant differences were noted after therapy $(\mathrm{p}=0.00001)$.

\section{Assessment of coughing and voice quality}

In the control group, coughs lasting for several seconds in the form of a single cough were noted in 29 patients (96\%) during the initial stage and in 26 patients (87\%) after 15 days of observation. In addition, one patient $(3 \%)$ at the initial assessment and four patients (13\%) at the final assessment presented no coughing.

In the study group, coughs lasting for several seconds in the form of a single cough were noted in 23 patients (77\%) before therapy and in 14 patients (46\%) after the provision of the original therapy for dysphagia (Tab. 4 and 5). The number of patients who did not cough increased from seven $(23 \%)$ to $16(53 \%)$. 
Table 3. Level and differences in time of swallowing assessed based on timed test of swallowing before and after therapy in study and control groups

\begin{tabular}{|c|c|c|c|c|c|c|}
\hline Swallowing time & $\bar{\chi}$ & SD & SE & $-95.00 \%$ & $95.00 \%$ & Mann-Whitney U test \\
\hline \multicolumn{7}{|c|}{ Before therapy (in seconds) } \\
\hline Total & 24.33 & 11.94 & 1.54 & 21.25 & 27.42 & \multirow{3}{*}{$0.38(p=0.71)$} \\
\hline Study group & 26.77 & 14.90 & 2.72 & 21.20 & 32.33 & \\
\hline Control group group & 21.90 & 7.49 & 1.37 & 19.10 & 24.70 & \\
\hline \multicolumn{7}{|c|}{ After therapy (in seconds) } \\
\hline Total & 19.18 & 9.13 & 1.18 & 16.82 & 21.54 & \multirow[t]{3}{*}{$-2.26(p=0.02)$} \\
\hline Study group & 17.10 & 10.30 & 1.88 & 13.25 & 20.95 & \\
\hline Control group group & 21.27 & 7.38 & 1.35 & 18.51 & 24.02 & \\
\hline
\end{tabular}

No significant differences in assessed coughing were observed between the study and control groups before therapy ( $p=0.06$, threshold value), whereas these differences were statistically significant after therapy $(\mathrm{p}=0.00009)$.

At the initial assessment, 30 patients (100\%) in the control group were observed to have slurred or very slurred speech, and this number did not change after 15 days of observation. At both initial and final assessments, no patient had normal speech in the control group.

In the study group, slurred and very slurred speech were noted in 30 patients (100\%) before therapy and in 12 patients (40\%) after the provision of the original therapy for dysphagia. Before therapy, no patients had normal speech, whereas after therapy 18 patients $(60 \%)$ exhibited it.

No significant differences in voice quality were observed between the study and control groups before therapy $(p=0.60)$, whereas these differences were statistically significant after therapy $(\mathrm{p}=0.00001)$.

\section{Assessment of swallowing time, number of swallows, and $\mathrm{SpO}_{2}$ level}

The average swallowing time decreased after therapy in the study group $(17.10 \pm 10.30 \mathrm{~s})$, and was much lower than in the control group ( $21.27 \pm 7.38 \mathrm{~s})$. Before therapy, the average swallowing time was $26.77 \pm 14.90$ s and $21.90 \pm 7.49$ s in the study and control groups, respectively. The Mann-Whitney $\mathrm{U}$ test showed that the differences between both groups were not statistically significant before therapy $(p=0.71)$, but of statistical significance after therapy $(\mathrm{p}=0.02)$ (Tab. 3 ).

The average number of swallows decreased after therapy in the study group $(5.23 \pm 1.61)$, and was lower than in the control group $(6.17 \pm 1.34)$. Before therapy, the average number of swallows was $7.17 \pm 3.05$ and $6.37 \pm 1.65$ in the study and control groups, respectively. The Mann-Whitney $\mathrm{U}$ test showed that the differences between both groups were significant after therapy ( $\mathrm{p}=0.02)$; however, no statistically significant differences in these values before therapy were noted $(\mathrm{p}=0.35)$.

Before therapy, $\mathrm{SpO}_{2}$ slightly decreased after the test in the study group $(95.50 \% \pm 1.91)$, which was higher than that in the control group $(94.90 \% \pm 2.01)$. Before the test, the $\mathrm{SpO}_{2}$ value was $96.23 \% \pm 1.79$ and $95.43 \% \pm 2.14$ in the study and control groups, respectively. The Mann-Whitney U test showed that, before and after the test, the differences in the $\mathrm{SpO}_{2}$ values before therapy were not statistically significant between both groups $(\mathrm{p}=0.14 ; \mathrm{p}=0.31$ ).

After therapy, $\mathrm{SpO}_{2}$ slightly decreased after the test in the study group $(96.03 \% \pm 1.87)$, which was higher than that in the control group $(95.20 \% \pm 1.67)$. Before the test, the $\mathrm{SpO}_{2}$ value was $96.53 \% \pm 1.70$ and $95.50 \% \pm 1.87$ in the study and control groups, respectively. The Mann-Whitney $U$ test showed that the differences between both groups were significant before the test $(p=0.04)$ and after the test $(p=0.03)$. Significant differences in $\mathrm{SpO}_{2}$ values after therapy were observed.

\section{Discussion}

The available literature lacks a comprehensive assessment of the effects of therapy for dysphagia in patients in the early post-stroke stage. Neurogenic dysphagia is assumed to emerge during the oral stage of swallowing and to manifest as difficulties in forming a bolus, chewing, shutting the mouth, and transporting the bolus around the oral cavity [13].

The literature indicates the possibility of improving tactile and thermal sensation through proper stimulations. It is assumed that the best-known therapeutic strategy for delayed swallowing reflex is tactile and thermal stimulation of the frontal palatine arches using a cooled laryngeal mirror. Most studies confirm the presence of cold receptors on the frontal palatine arches. It is assumed that the swallowing reflex may be stimulated via exposure of the palatine arches to low temperatures. Although the conducted tests indicate immediate improvement in the swallowing reflex, according to the authors, the lack of unequivocal results does not confirm the effectiveness of thermal stimulation as a therapeutic technique in the long-term perspective $[16,17]$.

Our own studies provided similar results, and indicated an immediate improvement in the swallowing reflex after application of stimulation to the frontal palatine arches using a laryngeal mirror previously cooled in ice. Furthermore, 
thermal stimulation of the palatine arches is assumed to trigger the pharyngeal and palatine reflexes [18].

It seems that the results of the timed test of swallowing confirm the effectiveness of the therapy applied. The test allowed the observation of a decrease in the number of swallows in the study group, which may indicate an improvement in swallowing function.

The average swallowing time in the study group significantly decreased after therapy; however, no significant difference in the swallowing time before or after therapy was observed in the control group.

In the available literature concerning tests of swallowing time, the authors indicate that the swallowing rate is a credible and important index for the assessment of swallowing disorders in patients with neurological ailments, which may be relevant to monitoring treatment response [19].

Our own studies showed an absence of coughing after therapy, which may indicate improvement in patients' swallowing function and lack of choking. A very important difference was observed in voice quality after swallowing between the study and control groups. After therapy, more than half of the patients in the study group exhibited normal speech, which may indicate a decreased risk of aspiration, although this has not been confirmed in the available literature.

The results of available studies investigating the relationship between aspiration and oxygen blood saturation are equivocal. According to some authors, a decrease in saturation by $2 \%$ may indicate aspiration of fluids during tests, whereas a decrease by more than $5 \%$ should prompt immediate termination of the test [20].

Desaturation occurs in patients after brain stroke but is related to food intake in some cases only [21-25]. One study reported a decrease in saturation by $2 \%$ and similarly by $4 \%$ in $52 \%$ and $14 \%$ of elderly patients without dysphagia, respectively [26]. It should be assumed that changes in oxygen blood saturation may be associated with various causes and there is no sufficient evidence linking desaturation to food aspiration [22, 27]. It follows from the latest research that saturation measurement is not a suitable tool for detecting aspiration in patients after vascular stroke [28]. Similarly, our own studies did not indicate a relationship between food intake and desaturation.

\section{Limitations of the study}

Our own studies covered a short observation period. Long-term therapy outcomes and differences between the study and control groups were not checked.

\section{Clinical implications/ /future directions}

After dysphagia therapy, an improvement in the swallowing reflex was noted in patients. It follows from the tests performed that the presented dysphagia therapy improves the swallowing function of patients after brain stroke.
However, in the future, it is recommended to conduct the research among a larger sample, and to check the effects of the presented physiotherapeutic treatment over a longer period.

\section{Conclusions}

A presented comprehensive therapy for dysphagia is effective and may reduce serious complications of swallowing disorders in clinical practice.

Conflicts of interest: The authors certify that there is no conflict of interest with any financial organisation regarding the material discussed in this manuscript.

Funding: This research was co-financed by the Physiotherapy Department of the Opole University of Technology.

\section{REFERENCES}

1. Guzik A. New directions in physiotherapy for patients after stroke. Przegląd Medyczny Uniwersytetu Rzeszowskiego i Narodowego Instytutu Leków w Warszawie. 2010; 8(4): 401-409.

2. Lauretani F, Saccavini M, Zaccaria B, et al. ICR2 Group. Rehabilitation in patients affected by different types of stroke. A one-year follow-up study. Eur J Phys Rehabil Med. 2010; 46(4): 511-516, indexed in Pubmed: 20414185.

3. Mozzanica F, Rosa S, Scarponi L, et al. Prevalence of dysphagia, malnutrition and dehydration at admission in a stroke unit. Otorinolaringologia. 2018; 17: 23-27, doi: https://doi.org/10.23736/S03926621.17.02137-3.

4. Bassim CW, Gibson G, Ward T, et al. Modification of the risk of mortality from pneumonia with oral hygiene care. J Am Geriatr Soc. 2008; 56(9): 1601-1607, doi: 10.1111/j.1532-5415.2008.01825.x, indexed in Pubmed: 18691286.

5. Dziewas R, Ritter M, Schilling M, et al. Pneumonia in acute stroke patients fed by nasogastric tube. J Neurol Neurosurg Psychiatry. 2004; 75(6): 852-856, doi: 10.1136/jnnp.2003.019075, indexed in Pubmed: 15145999.

6. Martino R, Foley N, Bhogal S, et al. Dysphagia after stroke: incidence, diagnosis, and pulmonary complications. Stroke. 2005; 36(12): 2756-2763, doi: 10.1161/01.STR.0000190056.76543.eb, indexed in Pubmed: 16269630.

7. Müller J, Wenning GK, Verny M, et al. Progression of dysarthria and dysphagia in postmortem-confirmed parkinsonian disorders. Arch Neurol. 2001; 58(2): 259-264, doi: 10.1001/archneur.58.2.259, indexed in Pubmed: 11176964.

8. Czernuszenko A, Litwin M, Zaborski J. Patofizjologia i konsekwencje kliniczne dysfagii neurogennej - część I. Neurologia Praktyczna. 2014A; 14(4): 23-28.

9. Czernuszenko A, Litwin M, Zaborski J. Rozpoznawanie i terapia dysfagii neurogennej - część II. Neurologia Praktyczna. 2014B; 14(6): 7-12.

10. Longo L, Ralli M, Clemente A, et al. Oral health status in elderly hospitalized patients with dysphagia: the role of dental hygiene. Otorinolaringologia. 2018; 18: 83-88, doi: 10.23736/S0392-6621.18.02148-3.

11. Holas MA, DePippo KL, Reding MJ. Aspiration and relative risk of medical complications following stroke. Arch Neurol. 1994; 51(10): 1051-1053, doi: 10.1001/archneur.1994.00540220099020, indexed in Pubmed: 7945003. 
12. Geeganage C, Beavan J, Ellender S, et al. Interventions for dysphagia and nutritional support in acute and subacute stroke. Cochrane Database Syst Rev. 2012; 10: CD000323, doi: 10.1002/14651858. CD000323.pub2, indexed in Pubmed: 23076886.

13. Litwin M. Dysfagia neurogenna. Neurologia po Dyplomie. 2013; 8(4): 43-50.

14. Hamdy S, Jilani S, Price V, et al. Modulation of human swallowing behaviour by thermal and chemical stimulation in health and after brain injury. Neurogastroenterology and Motility. 2003; 15(1): 69-77, doi: 10.1046/j.1365-2982.2003.00390.x.

15. Kaatzke-McDonald MN, Post E, Davis PJ. The effects of cold, touch, and chemical stimulation of the anterior faucial pillar on human swallowing. Dysphagia. 1996; 11(3): 198-206, doi: 10.1007/ bf00366386, indexed in Pubmed: 8755466.

16. Regan J, Walshe M, Tobin WO. Immediate effects of thermal-tactile stimulation on timing of swallow in idiopathic Parkinson's disease. Dysphagia. 2010; 25(3): 207-215, doi: 10.1007/s00455-0099244-x, indexed in Pubmed: 19707818.

17. Rosenbek JC, Robbins J, Fishback B, et al. Effects of thermal application on dysphagia after stroke. J Speech Hear Res. 1991; 34(6): 1257 1268, doi: 10.1044/jshr.3406.1257, indexed in Pubmed: 1787707.

18. Nowakowska H, Grabowska H, Mielnik M. Terapie wspomagające opiekę pielęgniarską nad pacjentami z zaburzeniami połykania. Problemy Pielęgniarstwa. 2012; 20(1): 126-132.

19. Nathadwarawala KM, Nicklin J, Wiles CM. A timed test of swallowing capacity for neurological patients. J Neurol Neurosurg Psychiatry. 1992; 55(9): 822-825, doi: 10.1136/jnnp.55.9.822, indexed in Pubmed: 1402974.

20. Lim SH, Lieu PK, Phua SY, et al. Accuracy of bedside clinical methods compared with fiberoptic endoscopic examination of swallowing (FEES) in determining the risk of aspiration in acute stroke patients.
Dysphagia. 2001; 16(1): 1-6, doi: 10.1007/s004550000038, indexed in Pubmed: 11213241.

21. Collins MJ, Bakheit AM. Does pulse oximetry reliably detect aspiration in dysphagic stroke patients? Stroke. 1997; 28(9): 1773-1775, doi: 10.1161/01.str.28.9.1773, indexed in Pubmed: 9303024.

22. Colodny N. Effects of age, gender, disease, and multisystem involvement on oxygen saturation levels in dysphagic persons. Dysphagia. 2001; 16(1): 48-57, doi: 10.1007/s004550000042, indexed in Pubmed: 11213246.

23. Roffe $\mathrm{C}$, Sills S, Wilde K, et al. Effect of hemiparetic stroke on pulse oximetry readings on the affected side. Stroke. 2001; 32(8): 1808-1810, doi: 10.1161/01.str.32.8.1808, indexed in Pubmed: 11486109 .

24. Rowat AM, Wardlaw JM, Dennis MS, et al. Does feeding alter arterial oxygen saturation in patients with acute stroke? Stroke. 2000; 31(9): 2134-2140, doi: 10.1161/01.str.31.9.2134, indexed in Pubmed: 10978042

25. Sherman B, Nisenboum JM, Jesberger BL, et al. Assessment of dysphagia with the use of pulse oximetry. Dysphagia. 1999; 14(3): 152156, doi: 10.1007/PL00009597, indexed in Pubmed: 10341112.

26. Hirst $\sqcup$, Ford GA, Gibson GJ, et al. Swallow-induced alterations in breathing in normal older people. Dysphagia. 2002; 17(2): 152-161, doi: 10.1007/s00455-001-0115-3, indexed in Pubmed: 11956841.

27. Leder SB. Use of arterial oxygen saturation, heart rate, and blood pressure as indirect objective physiologic markers to predict aspiration. Dysphagia. 2000; 15(4): 201-205, doi: 10.1007/s004550000028, indexed in Pubmed: 11014882.

28. Marian T, Schröder J, Muhle P, et al. Measurement of Oxygen Desaturation is Not Useful for the Detection of Aspiration in Dysphagic Stroke Patients. Cerebrovasc Dis Extra. 2017; 7(1): 44-50, doi: 10.1159/000453083, indexed in Pubmed: 28259883. 